\title{
Cost Estimation of Wind Farm with Battery-supported Output Power Limit Operation
}

\author{
Y. Yasuda ${ }^{1}$ and T. Funabashi ${ }^{2}$ \\ ${ }^{1}$ Department of Electrical Engineering and Computer Science \\ Kansai University \\ 3-3-35 Suita, Osaka 564-8680 (Japan) \\ Phone/Fax number: +81 66368 0978, e-mail: yasuda@mem.iee.or.jp \\ ${ }^{2}$ Meidensha Corporation \\ Think Park Tower, 2-1-1 Osaki, Shinagawa-ku, Tokyo 141-6029 (Japan) \\ e-mail: t.funabashi@ieee.org
}

\begin{abstract}
Due to shortage of a controllable capacity during night, a secondary battery is strongly expected to a newly installed grid-connected wind farms in some areas of Japan. However, the battery is nowadays too expensive for a wind farm developer to keep their generation cost competitive. It is therefore strictly needed to establish an optimal battery strategy to satisfy both of stability of output and cost-effective installation.

In this reports, a fundamental case study is discussed to estimate the cost for battery installation to a wind farm with output power limit operation. Using real wind condition data from a typical meteorological observatory, an annual electric energy generated from wind farms with various battery capacities is estimated regarding with a nighttime wind condition. As the result of the annual production estimation, it became clear the relationship between the battery capacity and the energy production cost.
\end{abstract}

\section{Key words}

Wind turbine, Secondary Battery, Output Power Limit Operation, Reservoir, Balancing.

\section{Introduction}

Wind power generation now achieves a remarkable breakthrough with $159-\mathrm{GW}$ worldwide install capacity at the end of 2009 [1]. In contrast, Japan's situation with $2,186 \mathrm{MW}$ at the end of 2009 would be just a symbolic "yellow signal" of the fact that Japan is almost certain to miss its goal for 3,000-MW installation by 2010 , which was the political target set by METI (Ministry of Economy, Trade and Industry) in 2001.

The main reason is considered to be Japan's special condition of electric network. The land of Japan extends from northeast to southwest, divided by a several cannels. Moreover, the country is divided to two different frequency areas at the middle of its land and the four main islands are divided into nine areas for nine gridoperating companies (see Fig.1). Although huge metropolitans with heavy electricity consumptions lie in "Tokyo", "Chubu" and "Kansai" grid areas, such areas have few suitable sites for wind power generation because of limited space due to highly populated areas in flat plains or steep mountains. On the other hand, windy and low-populated areas suitable for wind farm installation are distributed in "Hokkaido", "Tohoku" and "Kyushu" grid area (see Fig.2). As easily understood from the figure, a kind of "mismatch" between electricity consumption and installed wind power capacity can be seen in Japan presently.

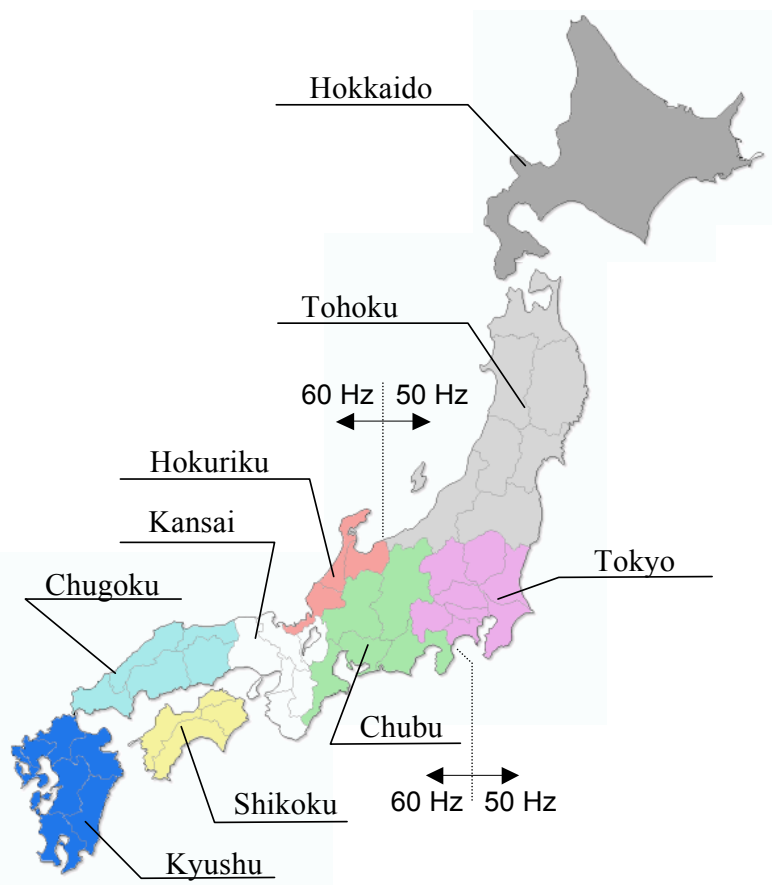

Fig.1. Nine grid areas in the main islands in Japan

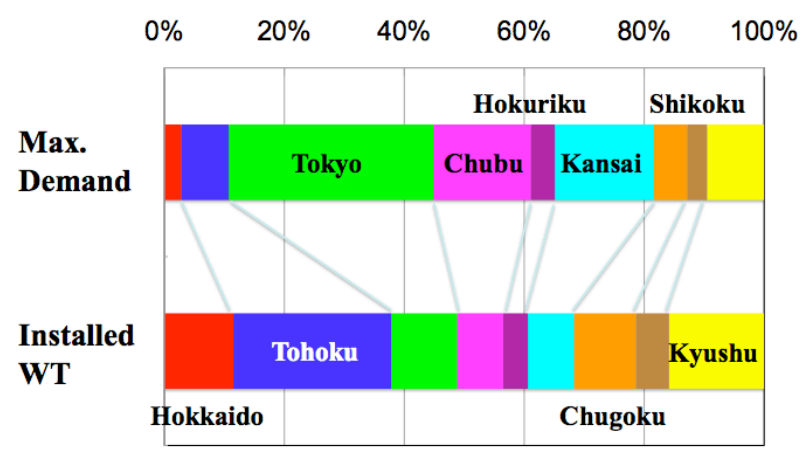

Fig.2. Maximum demands and installed wind turbines in nine utility grids in the main islands of Japan

(Data from NEDO web site, 2010 and METI web site, 2010) 
Regarding inter-grid connections, which are very familiar with grid systems in Europe and U.S., does not seems to contribute wind energy in Japan. Although inter-grid lines among the areas are certainly installed, their thermal capacities are not so enough (see Fig.3) and they are not permitted to flexibly use for wind power at present.

An interim report of the sub-committee on the wind power generation system, METI, Japan, 2005 reported as follows; 'According to a report "On detail design of future advisable electric industry" (May, 2004) from Electric Industry WG of Agency for Natural Resources and Energy, METI, Japan, it stated that "in use of an interconnection, in order to keep a system not to give advantage/disadvantage to all utility users and marketing forms ...". The rule of Electric Power System Council of Japan is provided on the basis on the above. However, these plans (Wind Power Interconnection) may lead to distribute the power from wind turbines via interconnection lines without regard to the rule, which would be problem under the existing scheme.' [3] Although several experimental trial to open the inter-grid connection are now planning to trade electricity between two or three grid areas, the expected capacity will be too small to push wide diffusion of renewables in near future. It is therefore undeniable that Japan has a more difficult environment to install wind power generation than the Western countries.

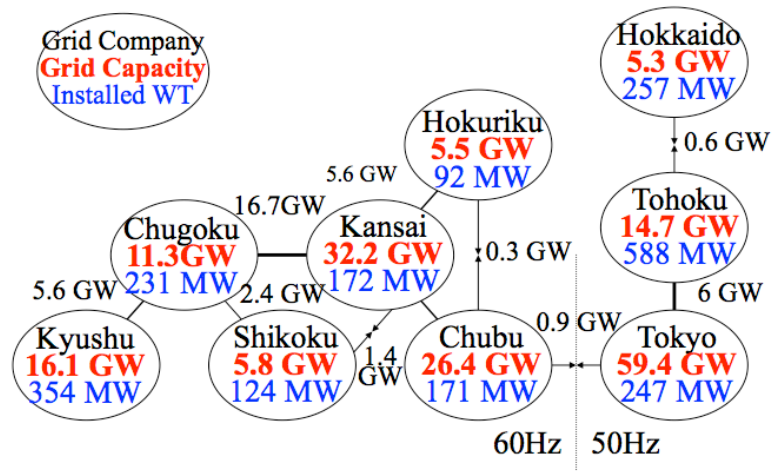

Fig.3. Nine utility grids and the interconnection lines between them in the main islands in Japan

(Data from NEDO web site, 2010 and METI web site, 2010)

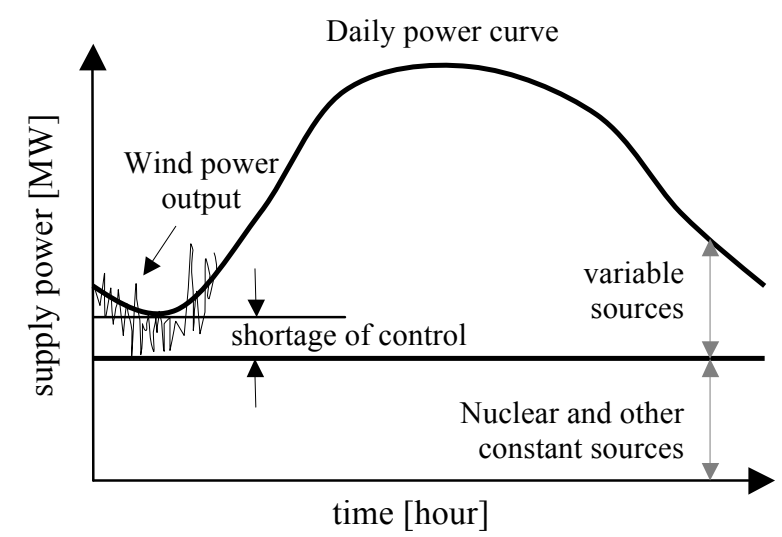

Fig.4. Conceptual figure of the relationship between wind power output and a shortage of controllable capacity
Because of above reason, although it is obliged to increase electric supply of the renewal energy origin to electric utility industry by the RPS (Renewables Portfolio Standard) law, it is ridiculed that "Japan's utilities have long been reluctant to take on more wind power whose variable supply risks destabilizing grid frequency" [2].

Several utilities (grid operators) in Japan in fact began to require wind turbine operators to release (parallel off) the turbines during several hours in night (normally from 11 p.m. to 5 a.m.), in which the controllable capacity of the grid is expected minimum as shown in Fig.4. The total hours for the parallel off are announced as 900 hours per year in the worst case. Otherwise, it is required to store electrical output in batteries before it is distributed rather than send the electricity directly into the network.

Such a requirement of parallel off or energy storage device will decrease utilized capacity or make additional installation cost, resulting to place an extra strain on wind turbine operators. The way forcing the additional the installation cost to turbine operators could be raise the power charge from wind and also could result to have a chilling effect against wind and renewable enthusiasm in Japan. Thus, the duration of the parallel off or the battery capacity should keep the minimum as far as possible, also satisfying the grid stability.

In this report, the authors propose a simple method how to estimate the electricity cost regarding battery capacity into a wind farm that is required to install to keep the grid stability. Using a real wind condition data from a metrological observatory, a wind speed distribution and an annual production will be discussed to estimate the total production during night and the effect of installed battery capacity.

\section{Estimation Method from Real Wind Condition Data}

To estimate the electricity costs against various installed battery capacities to store nighttime power production from wind turbines, it is important to consider how much watt-hour electric energy is expected during nighttime. In this chapter, the models and estimation method in the present analysis are described.

\section{A. Wind turbine and wind farm models}

The present model of a wind farm has ten wind turbines, which has a power rating of $1.0 \mathrm{MW}$ at $12 \mathrm{~m} / \mathrm{s}$. Therefore the maximum output power from the wind farm to the grid is $10 \mathrm{MW}$. The present model of a power curve of each turbine simply obeys an exact cubic curve against a wind speed when the wind speed is smaller than the rating wind speed of $12 \mathrm{~m} / \mathrm{s}$ (see Fig.5). Each turbine is simply supposed to operate equally in any moments from the exactly same wind speed all over the wind farm. Of course, detail model according to a real power curve of a specific turbine would be better if available. 


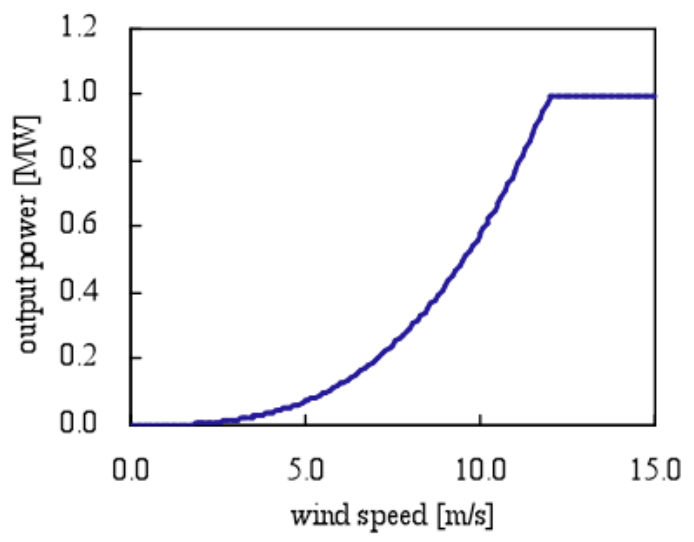

Fig.5. An ideal power curve of a wind turbine model

\section{B. Real data of wind condition}

A set of real data of annual wind condition is needed to estimate how much watt-hour the electricity is produced from wind especially during nighttime in winter season (in this paper, the "nighttime" is supposed to be 6 hours from 0 a.m. to 6 a.m. and the "winter season" to be 5 months from $1^{\text {st }}$ November to $30^{\text {th }}$ March). The employed wind condition data in this report is given from the web database of Japan Meteorological Agency [4], whose sampling time is 10 minutes and whose bin (the minimum resolution against wind speed) is $1.0 \mathrm{~m} / \mathrm{s}$. Note that the present employment of the JMA database is just for a simplified calculation to show a fundamental evaluation of the proposed estimation method. Better result would be taken with further information if the employing data were given from an observed data with $1.0-\mathrm{min}$ sampling and $0.1-\mathrm{m} / \mathrm{s}$ bin from the actual site if available.

\section{Battery model and output power limit operation}

Several grid-operators in Japan require to install energy storage device and to release (parallel off) the wind turbines from the grid during 900 hours per year (normally nighttime in winter) for wind turbine owners. If the duration of the parallel off is required for 6 hours per day during a winter season, the maximum capacity of a battery to be installed is calculated as follows; rating of battery $=$ rating of each wind turbine $\times$ number of turbines $\times$ parallel off hours $=1.0 \mathrm{MW} \times 10 \times 6$ hours $=$ $60 \mathrm{MWh}$. This would be an excessive duty for wind farm owners to raise construction cost and power charge of wind generation.

The authors therefore propose simple method to estimate the reasonable battery capacity to be installed. The concept of the considering operation does not required full-rating battery and allows an "output power limit" operation of each wind turbines. The schematic figures are illustrated in Fig.6.

In the present analysis, to simplify the calculation, the condition of the parallel off operation is supposed as follows;

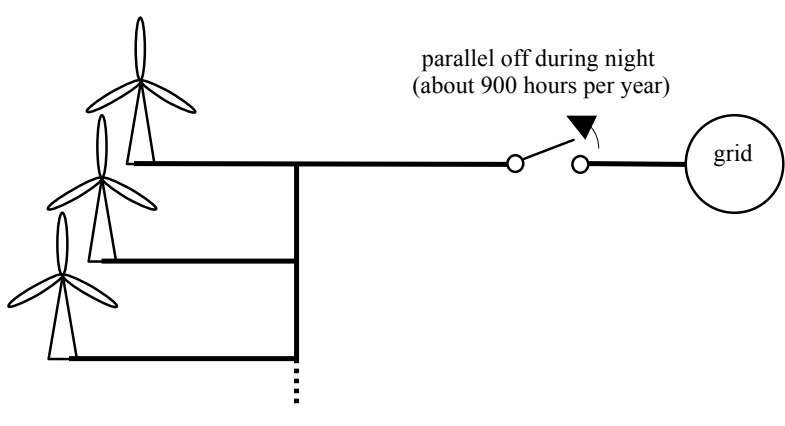

(a) conventional method without output power limit operation

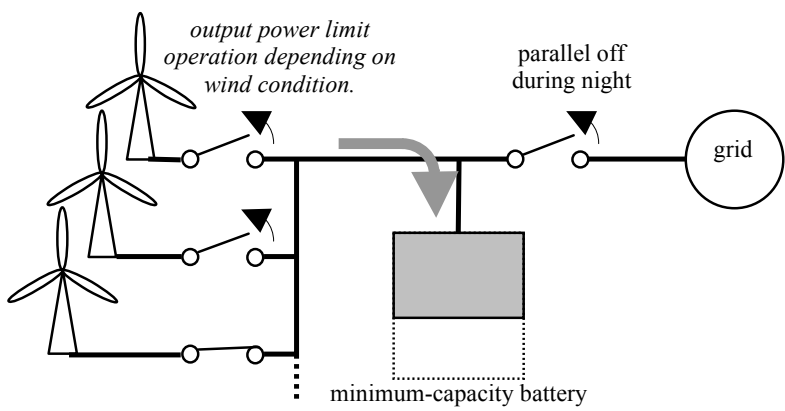

(b) output power limit operation with partial-rating battery

Fig.6. Conceptual diagram of wind farm with output power limit operation

(a) The output from wind farm is required to be completely released (paralleled off) from the grid during nighttime (from 0 a.m. to 6 a.m.) for grid stability. The period of the required parallel off is supposed to be 5-month winter season (from $1^{\text {st }}$ November to $30^{\text {th }}$ March).

(b) During the parallel off, a battery operates and stores the energy from the wind turbines. However, if the total electric energy from the turbines will be greater than the battery capacity, some of turbines will be controlled to limit their output.

(c) The battery is supposed as ideal. A margin capacity for lifetime and safety is not considered. Consequently, marginal operations such as a full $(0 \%)$ discharge and a full $(100 \%)$ charge are allowed in the present calculation. During daytime (from 6 a.m. to 12 p.m.), the battery is supposed to simply discharge the stored energy during the night to the grid. No special operation is considered to control wind output and grid stabilization.

\section{Cost Estimation}

To estimate a generation cost of the wind farm $c_{w f}$, the following equation is given;

$$
c_{w f}=\left(R e_{w}+\alpha R e_{b}+e_{d}\right) \times n P / E_{y e a r},
$$


where $e_{w}[\mathrm{yen} / \mathrm{kW}]$ is an installation expense of the wind farm, $e_{b}[\mathrm{yen} / \mathrm{kW}]$ is an installation expense of the battery, $e_{d}$ [yen $/ \mathrm{kW} /$ year] is an annual drive expense, $R[\%]$ is an expense rate per year, $P[\mathrm{~kW}]$ is an output rating of each wind turbine, $n$ is the number of turbines in the wind farm, $E_{\text {year }}[\mathrm{kWh}]$ is an annual output energy of the whole farm, and $\alpha$ is a parameter of a battery rating (from 0 to 1) against the total output capacity of the farm.

As a utility factor $U$ of the wind farm can be expressed as following equation,

$$
U=E_{\text {year }} /(n P \times 24 \times 365),
$$

eq.(1) can be rewritten as follows;

$$
c_{w f}=\left(R e_{w}+\alpha R e_{b}+e_{d}\right) /(U \times 24 \times 365) .
$$

In the present analysis, a set of cost conditions of a wind farm model is supposed as shown in Table 1. The annual output energy $E_{\text {year }}$ and the utility factor $U$ of the present wind farm model will be given by data analysis using real annual wind condition data.

Table 1. Cost conditions of a wind farm model

\begin{tabular}{|c|c|}
\hline site & Soya-misaki, Hokkaido \\
\hline $\begin{array}{c}\text { Rating output of wind } \\
\text { turbine: } P\end{array}$ & $1,000 \mathrm{~kW}$ \\
\hline Rating wind speed & $12 \mathrm{~m} / \mathrm{s}$ \\
\hline number of turbines: $n$ & 10 \\
\hline $\begin{array}{c}\text { Total capacity of the } \\
\text { wind farm: } n \times P\end{array}$ & $10,000 \mathrm{~kW}$ \\
\hline $\begin{array}{c}\text { Construction cost of the } \\
\text { wind farm: } e_{w}\end{array}$ & 250,000 yen/kW ${ }^{[9]}$ \\
\hline $\begin{array}{c}\text { Driving cost of the wind } \\
\text { farm per year: } e_{d}\end{array}$ & 3750 yen/ $/ \mathrm{kW}^{\text {year }}{ }^{[9]}$ \\
\hline $\begin{array}{c}\text { Installation cost of } \\
\text { a bttery: } e_{b}\end{array}$ & 280,000 yen/kW ${ }^{[8]}$ \\
\hline expense rate per year: $R$ & $7.8 \%{ }^{[8]}$ \\
\hline
\end{tabular}

\section{Analysis of Real Wind Condition Data}

To evaluate the electricity cost of the present model, an example of analyzing result using a real wind condition should be considered. As the example data in this report, the authors experimentally chose an annual wind data in 2006 from the observatory at Soya-Misaki Peninsula, which is one of the most windy site located on the northernmost point of Hokkaido.

Figure 7 is an annual report of an actually measured wind speed in 2006 at Soya-Misaki Observatory. Figure 7 also shows examples of monthly reports of the wind speed in January (month with strongest average wind) and August (month with weakest) at the site. From Fig.8(b), it is clear that there is no day that has a wind speed more than 12$\mathrm{m} / \mathrm{s}$ turbine rating in a typical weak-wind month. It means that the installation of a full-rating (wind turbine rating $\times$ number of turbine $\times$ parallel off hours) battery may not be always needed.

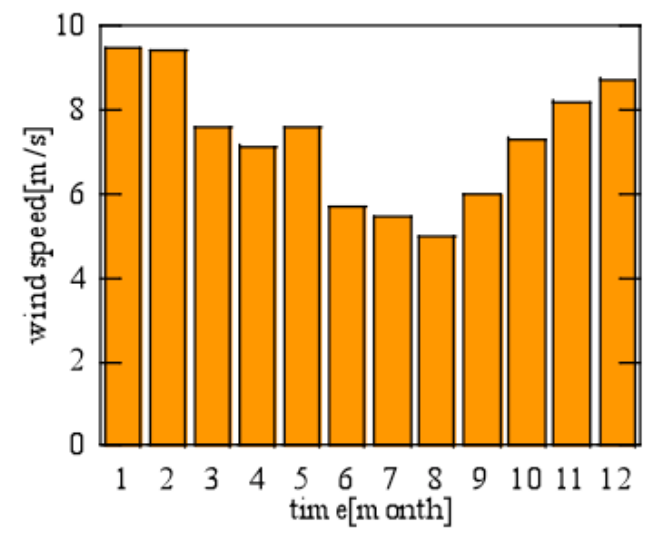

Fig.7. Annual wind speed distribution in 2006
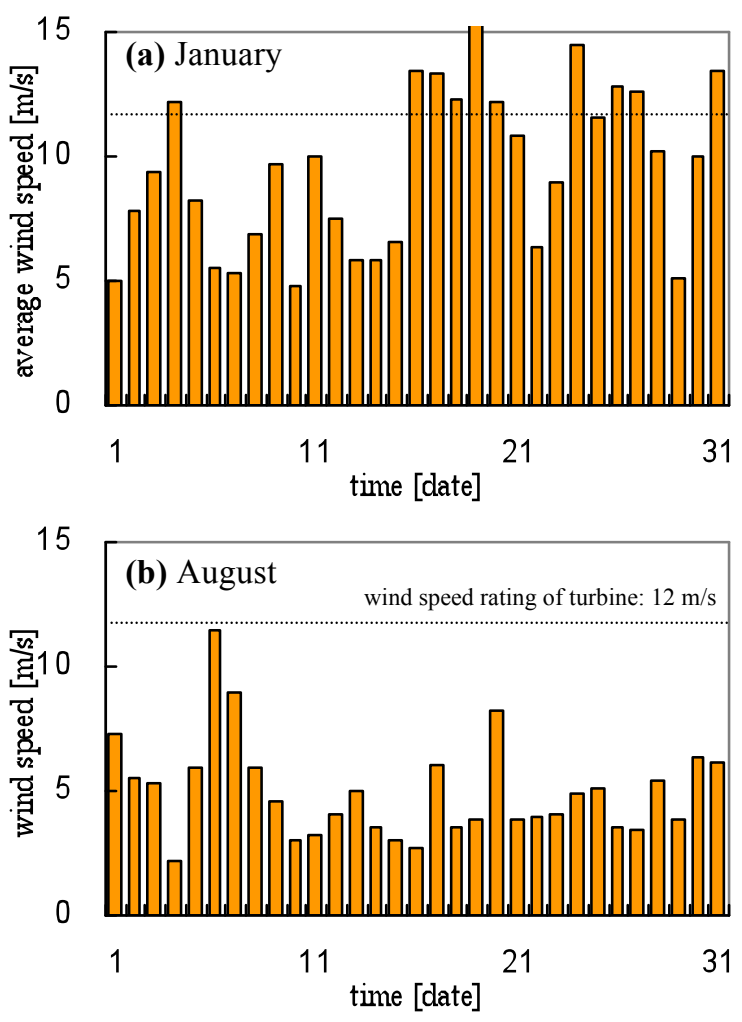

Fig.8. Examples of monthly reports of wind speed at the sample site in 2006

For more detail discussion, the annual distribution of wind speed is reconstructed in Fig.9. Especially in Fig.9(b), the distribution of wind speed during nighttime (from 0 a.m. to 6 a.m.) is extracted from the annual data. It is evident from Fig.9(b) that the days that have strong wind more than $12 \mathrm{~m} / \mathrm{s}$ rating during nighttime account for only less than $15 \%$ of the total annual distribution.

From above analysis using a real wind condition data, the installation of a full-rating battery is concluded to be too excessive. Therefore, it becomes clear that the consideration on the reasonable battery capacity should be needed. 

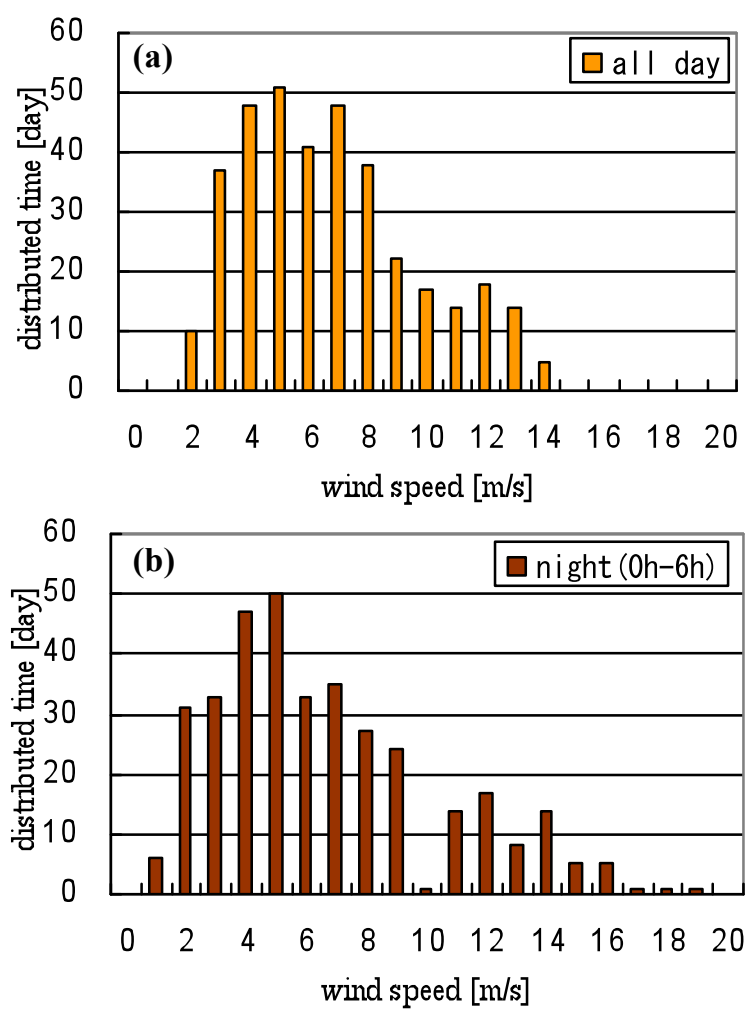

Fig.9. Annual wind speed distribution in 2006

\section{Estimation of electricity costs}

In this chapter, a calculation varying the battery capacity is discussed to investigate how much effect will be given if the installing battery capacity is reduced from full rating.

Figure 10 shows that the estimated distribution of output power from the 10 wind turbines calculated according to the power curve in Fig. 5 using the real wind condition at Soya-Misaki in 2006. This graph indicates the case with the full-rating battery of $10 \mathrm{MW}$. Note that the energy during daytime (from 6 a.m. to 12 p.m.) and nighttime (from 0 a.m. to 6 a.m.) in summer season (from April to October) is directly distributed to the grid and that during nighttime in winter season (from January to March, and from November to December) is once stored to the battery and is discharged to the grid in the daytime.

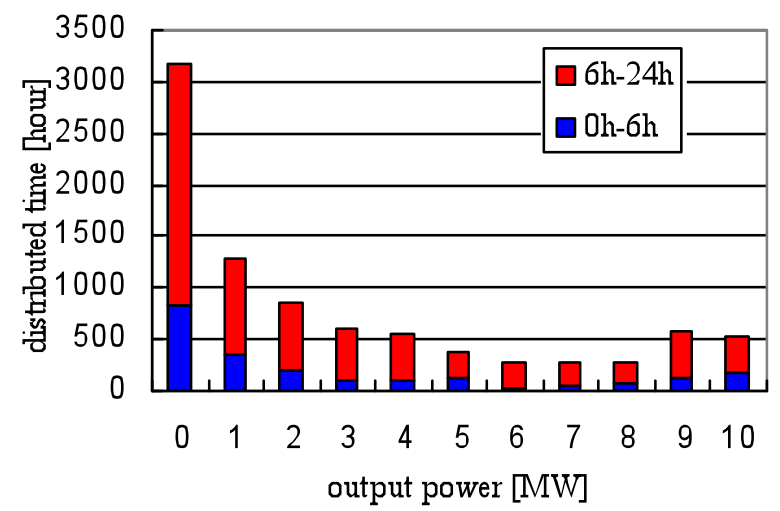

Fig.10. Estimated distribution of output power
If the installed battery is designed to have $60 \%$ capacity, i.e. $6 \mathrm{MW}$, the distribution of the storing energy during night will change as shown in Fig.11. In this case, since the battery capacity cannot store electricity no more than $6 \mathrm{MW}$, the bars on more than $7 \mathrm{MW}$ has been eliminated. During the total output from the 10 turbines exceeds the limited rate of $6 \mathrm{MW}$, several turbines are controlled to limit their outputs and the total power flow into the battery were limited no more than $6 \mathrm{MW}$. Consequently, the bar on $6 \mathrm{MW}$ in Fig. 11 apparently increases.

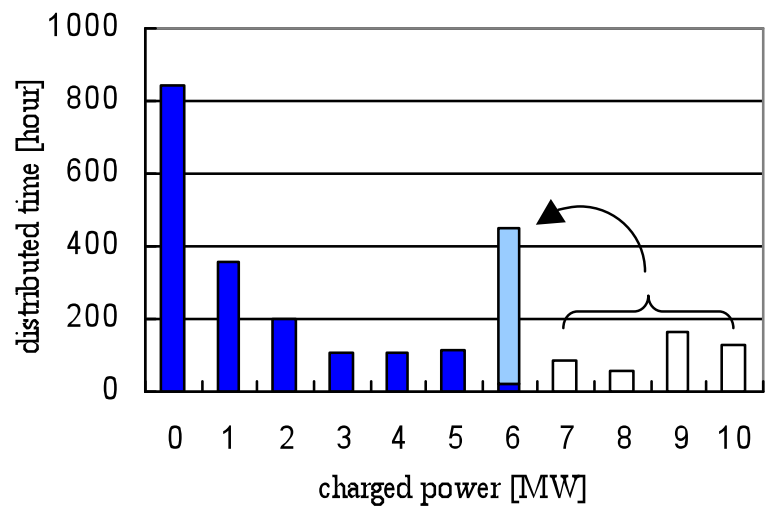

Fig.11. Estimated distribution of output power during nighttime in case of $60 \%$-rating battery

The partial-rating battery with the output power limit operation in the wind farm may cause some deterioration of the utilized capacity. However, the degree of the deterioration is expected to be much smaller than that in case of a complete parallel off without a battery. It is also expected that the installation cost in case of reduced capacity is much lower than that of a full-rating battery.

Finally, to evaluate how much effect will be given according to the reduction of battery capacity, checking all wind speed data during the year, the calculation results as shown in Figs. 12 and 13 are achieved. Figure 12 describes how much annual utility factor will be degraded depending upon capacity reduction of the battery. According the graph of the present site, the annual utility factor of the wind farm is expected $33.3 \%$ at the site (Soya-Misaki) in case of the full-rating battery $(100 \% ; 10 \mathrm{MW} \times 6$ hours $=60 \mathrm{MWh})$. It is also understood from the graph that the complete parallel off operation without battery $(0 \%, 0 \mathrm{MWh})$ during 6-hours nighttime causes significant degradation of the utility factor to $28.3 \%$.

On the other hand, the estimated generation cost was given as a linear curve from $9.4 \mathrm{Yen} / \mathrm{kWh}$ to 15.5 $\mathrm{Yen} / \mathrm{kWh}$ as shown in Fig.13. A profitable line of wind business is generally considered to be $30 \%$ for a utility factor and around 11 yen for generation cost, respectively. Therefore, an additional secondary battery with no more than 20\%-rating may be tolerate for wind turbine operators, some of which in Japan in fact have installed low-rating batteries to satisfy both the requirement from grid-operator and their own profitability. 


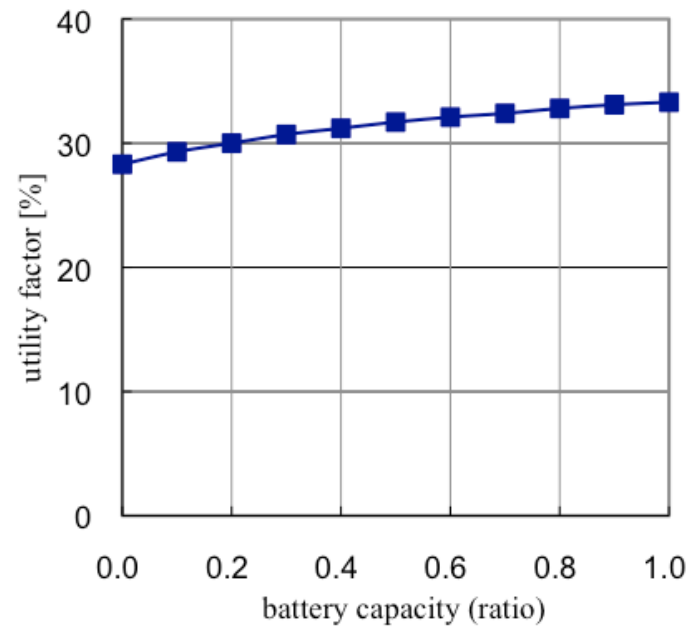

Fig.12. Calculated result (utility factor)

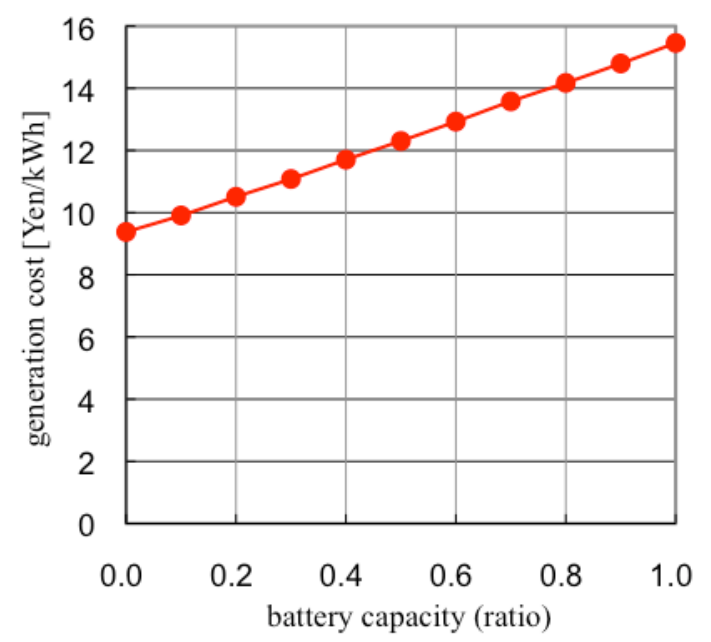

Fig.13. Calculated result (generation cost)

\section{Conclusions}

This report shows a proposal of cost estimation method of a wind farm with battery and output power limit operation for grid stabilization. The authors focused on a real wind condition data and analyzed daily, monthly and annual report from an observatory to clarify how much degree the wind speed more than rating is distributed. After analyzing the wind condition data and calculation of annual production of wind power, curves of an utility ratio and a generation cost against battery capacity was summarized.

Since the profitable line of a utility factor for commercial operation is commonly considered as $30 \%$, the primitive minimum battery capacity to install to the present site is determined to $20 \%$ of the original full-rating capacity. Of course, simply speaking, the best option from the profitable viewpoint of a turbine operator might be "no battery" and "no parallel off", which is clearly shown in the result. However, it seems to be difficult to install new wind farm without a secondary battery in Japan at present. And, the problem in today's Japan is a downsized model that might occur in tomorrow's Europe.

The utility factor curve and the generation cost curve against battery capacity would change depending upon a wind condition at an observatory or a wind farm site. However, the methodology proposed in this report will help to estimate a utility factor and a generation cost depending upon the site using a real wind condition data.

\section{References}

[1] [1] Global Wind Energy Council: "Global wind power boom continues despite economic woes", 2010. http://www.gwec.net/fileadmin/documents/PressReleases/P R_2010/Annex\%20stats\%20PR\%202009.pdf

[2] E. Prideaux: "Storing Up Trouble in Japan", Windpower Monthly, Vol.23, No.6, pp.61-63 $(2007,6)$

[3] Ministry of Economy, Trade and Industry: "Minutes of Subcommittee on Grid Interconnection of Wind Power, New and Renewable Energy Subcommittee, Advisory Committee for Natural Resources and Energy" [in Japanese]

http://www.meti.go.jp/committee/gizi_8/8.html

[4] Japan Meteorological Agency, "Meteorological Database in past" [in Japanese]

http://www.data.jma.go.jp/obd/stats/etrn/index.php 